\title{
Determination of Candidate Breeding Resource from Sri Lankan Traditional Rice Mudukiri Al
}

\author{
P.D.C. Padukkage ${ }^{1}$, S. Geekiyanage ${ }^{2 *}$ \\ ${ }^{1}$ Faculty of Graduate Studies, University of Ruhuna, Sri Lanka \\ ${ }^{2}$ Department of Agricultural Biology, University of Ruhuna, Sri Lanka \\ *sudarshanee@agbio.ruh.ac.lk
}

\begin{abstract}
Most of the traditional rice varieties conserved at Plant Genetic Resources Centre, Sri Lanka, possess more than one accession. Determination of morphological variation and yield potential among accession within same variety would be useful for breeding new varieties and farmer introductions. Six accessions of Mudukiri Al variety were selected for this study. The objective of this study was to determine the morphological variation among accessions of Mudukiri Al for selecting candidates for future breeding. Six accessions obtained from the Plant Genetics Resources Centre, Sri Lanka, were grown in Kamburupitiya with three replicates in a completely randomised design from November 2013. Days to fifth leaf (DFL), seedling height at fifth leaf (SHT), leaf area of fifth leaf (LA), days to flowering (DF), plant height at flowering $(\mathrm{PH})$, culm number at flowering $(\mathrm{CN})$, total number of panicles $(\mathrm{PN})$, number of grains per first panicle (GN), grain length (GL) and width $(\mathrm{GW})$ were recorded which varied from 51 to 59 days, 63.8 to $80.3 \mathrm{~cm}, 6.5$ to $44.4 \mathrm{~cm}^{2}, 86$ to 102 days, 112.7 to $148.6 \mathrm{~cm}, 16$ to 38,7 to 29,103 to $255,0.7$ to $0.9 \mathrm{~cm}$ and 0.3 to $0.4 \mathrm{~cm}$ respectively. Accession 4,144 produced significantly higher GN of 255 while accession 3,970, 4,145 and 3,758 produced 184, 160 and 166 respectively. Accessions 3,970 and 5,536 were with short awns. A positive correlation between DFL and PH (0.870) had been observed. Higher GN and the highest $\mathrm{CN}$ (38) would be favourable for selecting accession 4,144 as a candidate breeding resource.
\end{abstract}

Keywords: Mudukiri Al, Morphological variation, Breeding resource 